\title{
LINKING SOIL BACTERIAL COMMUNITY AND CROP YIELD IN A WHEAT (TRITICUM AESTIVUM L.) - ALFALFA (MEDICAGO SATIVA L.) INTERCROPPING SYSTEM
}

LI, X. $.^{1,2,3}-$ ZHAO, Y. S. $.^{*}-$ SUN, G. Y. $.^{2,4^{*}}-$ JIN, W. W. ${ }^{2}-$ SUN, M. L. ${ }^{5}-$ ZHANG, H. H. ${ }^{3}-$ XU, N. ${ }^{6}$ - CAI, D. J. ${ }^{7}-$ LI, D. M. ${ }^{8}$

${ }^{1}$ School of Forestry, Northeast Forestry University, Harbin, 150040, China

${ }^{2}$ College of Life Science, Northeast Forest University, Harbin, 150040, China

${ }^{3}$ College of Resources and Environment, Northeast Agricultural University, Harbin 150030, China

${ }^{4}$ Key Laboratory of Saline-Alkali Vegetation Ecology Restoration, Ministry of Education, Northeast Forestry University, Harbin, 150040, China

${ }^{5}$ Institute of Crop Breeding, Heilongjiang Academy of Agriculture Sciences, Harbin, 150040, China

${ }^{6}$ Natural Resources and Ecology Institute, Heilongjiang Academy of Sciences, Harbin, 150040, China

${ }^{7}$ Institute of Crops, Heilongjiang Academy of Land Reclamation and Agricultural Sciences, Jiamusi, 154000, China

${ }^{8}$ Department of Product Distribution, Forestry Department of Heilongjiang Province, Harbin, 150040, China

*Corresponding authors

e-mail/phone: zhaoys1957@163.com/+86-451-8219-1501; sungy@vip.sina.com/+86-451-

8219-1507

(Received $18^{\text {th }}$ Dec 2019; accepted $6^{\text {th }}$ May 2020)

\begin{abstract}
Diverse intercropping has been utilized to improve crop productivity on agricultural fields. Beneficial plant rhizobacteria are associated with plant root surface and may increase yield. In the research, the bacterial communities in soils of monoculture and intercropping wheat and alfalfa (cv. Winter star) were studied using MiSeq sequencing of the 16S rDNA gene. Intercropping pattern improved wheat yield in the field. The dominant taxonomic groups in the rhizosphere soil were Proteobacteria, Acidobacteria, Bacteroidetes, Actinobacteria, Planctomycetes, Chloroflexi and Nitrospirae and these were present across 4 samples. Intercropping significantly affected the diversity and composition of bacterial communities compared to monoculture. The enrichment of bacterial communities such as the populations of Rhizobiales, Burkholderiales, Pseudomonales and Bacillus could be important factors contributing to yield increases in intercropping wheat. In addition, some populations, such as Sphingomonadals and Xanthomonadales, indicated contrary changes, their diversity declined in intercropping systems, meaning that these bacterial populations were affected by cropping patterns.
\end{abstract}

Keywords: monoculture, intercropping, bacterial community composition, MiSeq, rhizosphere

\section{Introduction}

Intercropping has been used for many years to grow two or more plants in the same area of land simultaneously (Vandermeer, 1992). Intercropping ecosystems have 
demonstrated to be better than monoculture in terms of yields as a consequence of intercropping can make better use of one or more agricultural resources in time and space, through different rooting depths or over a year, to maximum the access to nutrients (Ma et al., 2017; Ren et al., 2017; Sylvain et al., 2018). Furthermore, the advantage of intercropping systems in yield is due to the interaction between intercropped species on the above- and below-ground (Du et al., 2011; HauggaardNielsen et al., 2001). There are more reports about interspecies above-ground than below-ground interactions for interspecies interactions (Vandermeer, 1992; Willey, 1999). However, the effects of below-ground may be greater than above-ground species interactions for intercrop productivity (Hanming et al., 2012; Yue et al., 2014). There are compact relationships between yield advantage and water content, root morphologies nutrient uptake and root-associated microbes in intercropped soils (Choudhary et al., 2016; Zhou et al., 2011).

Intercropping of leguminous crops and cereals is one of the most practical intercropping techniques (Hesler and Kieckhefer, 2018) for improving crop yields and land use efficiency (Bhatti et al., 2006). Therefore, perennial alfalfa and annual wheat were selected to set up intercropping system in our study. In consequence, the root morphological and physiological characteristics of alfalfa and wheat are very different, and co-cultivation of both species can improve the absorption of water and nutrients by the root system (Skelton and Barrett, 2005). Leguminous plants could improve harsh environmental conditions or the available resources for other adjacent species by transferring of symbiotically fixed nitrogen $(\mathrm{N})$ (Jensen, 1996a) and dissolving of inorganic phosphorus (P) fixed in soil (Yan et al., 1996). Furthermore, intercropping may increase soil microbial diversity, which usually has a positive effect on crop productivity (Xin et al., 2016). Free-living microorganisms strongly regulate plant productivity by mineralizing and competing nutrients that maintain plant productivity (Van Der Heijden et al., 2008).

Microorganisms are ubiquitous in the environment and play an essential role in the global biogeochemical cycles that sustain all life on Earth ( $\mathrm{Su}$ et al., 2012; Zarraonaindia et al., 2013). It is well known that soil microbes carry out fundamental processes that contribute to nutrient acquisition (Li et al., 2016, 2020), nitrogen cycling (Li et al., 2017), carbon cycling (Schimel and Schaeffer, 2012) and soil formation (Rillig and Mummey, 2006). Soil microbes are crucial regulators of plant productivity (Van Der Heijden et al., 2008), and plant community composition considerably influences the community composition of rhizosphere microbes. The aboveground trophic interactions have indirect effects on soil biota by affecting the quantity and quality of resources that plants produce (Wardle et al., 2004). The roots of different plant species are in direct contact in intercropping ecosystem, and the root-associated communities of both plants species can therefore interact. The resulting microbial community composition is likely to be a mixture of the species-specific communities but may be dominated by the community composition of one plant species (Song et al., 2007). However, while it is widely recognized that microbes perform crucial roles in biogeochemical cycling, the impact of soil microbes on plant productivity is still poorly understood. Therefore, in order to better understand the changes of bacterial communities of monoculture versus intercropped plants in soils, 16S rDNA gene-based MiSeq sequencing approach was employed in wheat/alfalfa intercropping system, which may contribute to the greater yield in intercropping compared with sole cropping. 


\section{Materials and methods}

\section{Field plots}

A field experiment was conducted at Heilongjiang Academy of Land Reclamation and Agricultural Sciences, Jiamusi city of Heilongjiang province, China (latitude, $46^{\circ} 46^{\prime} \mathrm{N}$; longitude, $130^{\circ} 27^{\prime} \mathrm{E}$ ) in 2014 . The region has a typical temperate continental climate with an average annual temperature of $-3.0 \sim-1.5^{\circ} \mathrm{C}$ and the mean temperature of $20^{\circ} \mathrm{C}$ in July. The mean annual precipitation is $450 \sim 550 \mathrm{~mm}$ and nearly $59 \%$ of total rainfall is received by northwest monsoons from July-September. The active accumulated temperature $\left(\geq 10{ }^{\circ} \mathrm{C}\right)$ is $2000 \sim 2800{ }^{\circ} \mathrm{C}$ per year, and a frost-free period of 115 130 days. The soil is classified as a meadow black soil. Soil samples contained organic of $3.9 \%$, available nitrogen of $46.9 \mathrm{mg} \cdot \mathrm{kg}^{-1}$, available phosphorus of $145.5 \mathrm{mg} \cdot \mathrm{kg}^{-1}$, available potassium of $121.0 \mathrm{mg} \cdot \mathrm{kg}^{-1}, \mathrm{pH}$ of 6.7 .

The experimental design was a plot divided into three blocks (three replicates), each block being further divided into three plots. Each plot was used for one of the following cropping systems: (1) wheat monoculture, (2) alfalfa monoculture, and (3) wheat intercropped with alfalfa. The experiment covered an area of $405.8 \mathrm{~m}^{2}$. Each plot unit comprised 12 rows that were $5 \mathrm{~m}$ long and $0.66 \mathrm{~m}$ wide, each $39.6 \mathrm{~m}^{2}$ in size. Plots and blocks were separated from each other by 1-meter walkways. For the intercropped treatment, two alfalfa rows were intercropped with two rows of wheat. The single cropping plots consisted of 12 rows of one plant species. Edges of each plot were sown with a mix of wheat and alfalfa to minimize edge effects but these plants were not included in the harvest.

The wheat (Triticum aestivum L. cv. Kenfeng No.1) and alfalfa (Medicago sativa L. cv. Winter star) were sown manually on 10 and 14 June 2014, respectively. Seedlings in each row were thinned after emergence to leave a density of 30 plants $\mathrm{m}^{-2}$ for alfalfa and 600 plants for wheat. Prior to sowing, fertilizer in the form of $\left(\mathrm{NH}_{4}\right)_{2} \mathrm{HPO}_{4}\left(150 \mathrm{~kg} \cdot \mathrm{hm}^{-}\right.$ ${ }^{2}$ ) were applied and the soil was disked to a depth of $10 \mathrm{~cm}$. A conventional herbicide treatment was applied.

The yield of wheat and alfalfa was investigated using the quadrat harvesting method, and was determined in August 2014. The plants were killed at $105{ }^{\circ} \mathrm{C}$ for $30 \mathrm{~min}$ and dried at $60^{\circ} \mathrm{C}$ to a constant weight.

Soil samples were collected from three different sampling sites at the flowering stage on 26 July 2014. Non-rhizoshpere soil were removed by shaking the root gently, Rhizosphere soils, adhering to the roots (Nazih et al., 2001), were placed into sterile petri plates. Three random sampling points were chosen for each sampling plot. Nine random single samples of rhizosphere soil were collected and thoroughly mixed in order to obtain a composite sample. The soil samples were sieved $(2 \mathrm{~mm})$ and stored at $-80{ }^{\circ} \mathrm{C}$ until DNA extraction.

\section{DNA extraction and PCR amplification 16S rRNA}

The genome DNA was isolated using an Omega Bio-Tek E.Z.N.A. Soil DNA Extraction Kit (Omega Bio-Tek, Atlanta, GA, USA) according to the manufacturer's instructions. The equality of extracted DNA was examined following electrophoresis in a $1 \%$ agarose gels. The V4-V5 regions of the $16 \mathrm{~S}$ rRNA gene were PCR amplified by using barcoded fusion primers 515F (5'-GTGCCAGCMGCCGCGG-3') and 907R (5'-CCGTCAATTCMTTTRAGTTT-3'). For each sample, three independent amplification reactions were performed. The reaction mixture $(20 \mu \mathrm{L})$ contained $5 \mu \mathrm{M}$ 
of each primer, $\sim 10 \mathrm{ng}$ of template DNA, $5 \times$ FastPfu PCR buffer, $2.5 \mathrm{mM}$ dNTPs and $2.5 \mathrm{U}$ of FastPfu DNA Polymerase (MBI, Fermentas, USA). The amplification conditions were: $95^{\circ} \mathrm{C}$ for $3 \mathrm{~min}$ and 7 cycles of denaturation at $95{ }^{\circ} \mathrm{C}$ at $30 \mathrm{~s}$, annealing at $55{ }^{\circ} \mathrm{C}$ for $30 \mathrm{~s}$, and extension at $72{ }^{\circ} \mathrm{C}$ for $45 \mathrm{~s}$, followed by a final extension period at $72{ }^{\circ} \mathrm{C}$ for $10 \mathrm{~min}$. During amplification, a negative control reaction (lacking template DNA) was included to check the experimental contamination. All reactions were performed in triplicate. The PCR products were detected by electrophoresis in a 2\% agarose gel and purified using the AxyPrep DNA Gel Extraction Kit (Axygen Biosciences, Union City, CA, USA).

\section{MiSeq sequencing and data analysis}

The Illumina MiSeq PE250 was applied to perform barcoded V4-V5 amplicons by Shanghai Majorbio Bio-Pharm Biotechnology (Shanghai, China). Raw fastq files were demultiplexed and quality-filtered using QIIME (version 1.17). Sequences were clustered and assigned to operational taxonomic units (OTUs) at a 97\% similarity level using UPARSE (version 7.1). To assess phylogenetic affiliations, taxonomic ranks were assigned to each sequence using Ribosomal Database Project (RDP). Compositional differences between libraries were determined using distance matrices and LIBSHUFF comparisons (Singleton et al., 2001). Alpha diversity (Ace, Chao 1, Simpson and Shannon) was calculated with QIIME (Version 1.7.0) and displayed with R software (Version 2.15.3). Venn diagrams of unique and OTUs (0.03 cut-off value) were drawn to highlight the similarities and shared sequences between the different analyzed samples. Principal Component Analysis (PCA) in genus level was performed using ggplot2 package in $\mathrm{R}$ software (Version 2.15.3). Hierarchical cluster (Heatmap) analyses were generated in MOTHUR using the gplots package of R software (Version 2.15.3).

\section{Statistical analysis}

We used SPSS for windows (version 19$)$ to test for significance $(P<0.05)$ between treatments of relative abundances, Alpha diversity and richness of bacterial communities using Duncan post-hoc test at 95\% confidence level. To determine the key factor(s) affecting microbial parameters, stepwise multiple regression analysis was applied using the probability criteria of $P<0.05$ to accept and $P>0.1$ to remove a variable from the analysis.

\section{Results}

\section{Plant yields}

The yield of wheat and alfalfa were measured in September 2014 (Fig. 1). The intercropping significantly increased wheat yield compared with monoculture $(P<0.05)$. The yield in the intercropped wheat was $39.65 \%$ higher than monoculture. However, intercropping systems slightly decreased the biomass of alfalfa and there was no significant difference between monoculture and intercropping treatments $(P>0.05)$. 


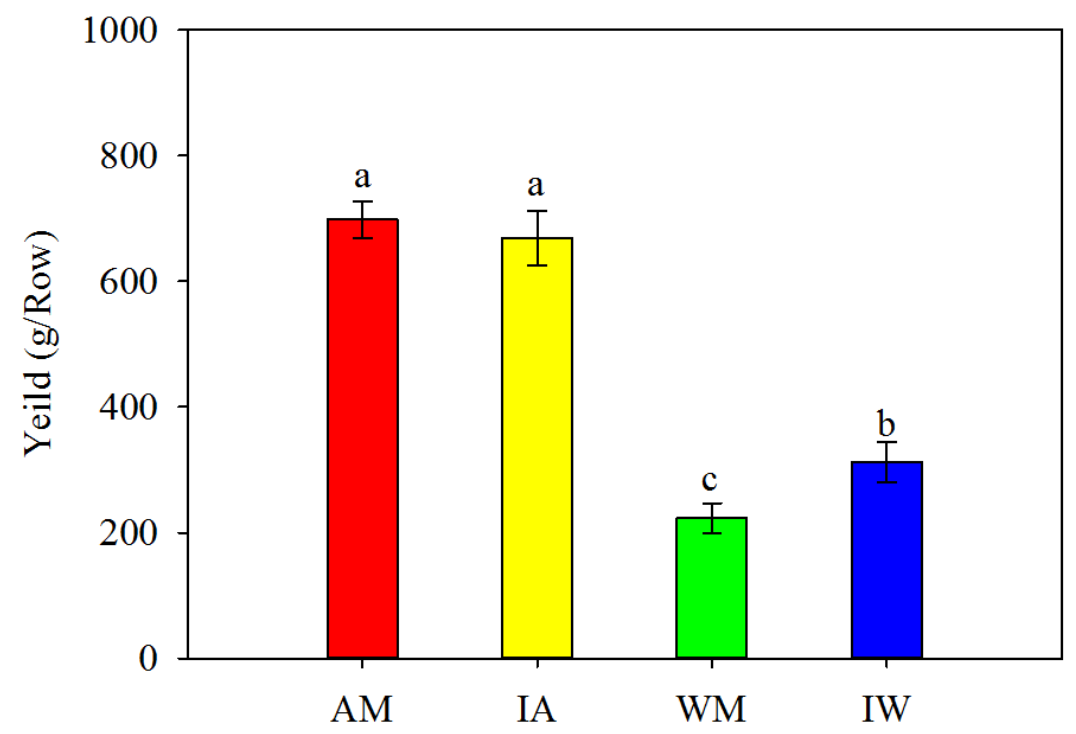

Figure 1. The yield of wheat and alfalfa. Alfalfa monoculture (AM), intercropping alfalfa (IA), wheat monoculture (WM), and intercropping wheat (IW). Bars with different letters indicate significant difference at $P<0.05$. The significant differences between the means were determined using Duncan post-hoc test

\section{Bacterial community analysis}

A total of 148,259 paired-end $\geq 300$-bp reads were acquired from all 12 samples, with $31,242,42,231,39,239$ and 35,547 high quality reads at the monoculture alfalfa, alfalfa intercropping, monoculture wheat, and wheat intercropping soils, respectively (Table Al in the Appendix). The average read length was $396 \mathrm{bp}$. Based on $97 \%$ species similarity, 1,231, 1,188, 1,161 and 1,280 operational taxonomic units (OTUs) were obtained from monoculture alfalfa, alfalfa intercropping, monoculture wheat, and wheat intercropping soils, respectively.

\section{Bacterial diversity and richness}

To determine rarefaction curves and other measures of diversity, OTUs (operational taxonomic units) were identified at 3\% genetic distance. Rarefaction curves indicated consistent differences in all 4 libraries (Fig. Al in the Appendix). At 3\% genetic distances, almost all rarefaction curves reached saturation, indicating that the surveying effort covered almost the full extent of taxonomic diversity at this genetic distance.

The comparison of mean Chao 1 richness estimates of alfalfa rhizosphere soils and wheat rhizosphere soils showed no differences at genetic distances of 3\% (421 OTUs and 424 OTUs, respectively) (Table 1). Analysis of differences of cropping pattern by at genetic distances of $3 \%$ showed that the intercropping patterns varied in the predicted number of OTUs $(P>0.05)$. The uniform conclusion was seen using the Ace richness index (Table 1). Moreover, the comparison of the mean Shannon diversity index of 4 libraries revealed that the highest bacterial diversity at analyzed genetic distances was found in intercropping wheat and alfalfa soils, followed by monoculture wheat and alfalfa. The predicted richness and diversity in the intercropping rhizosphere soils exceeded that of the corresponding monoculture soils. Meanwhile, an influence of plant species on bacterial diversity was observed. Wheat soils demonstrated higher diversity 
than corresponding alfalfa in different cropping patterns. Thus, both intercropping system and plant species impacted overall bacterial diversity and richness.

Table 1. The diversity index of 4 libraries. Means of three replicates \pm SE. Different letters following the mean values within each column indicates significant differences at $P<0.05$

\begin{tabular}{c|c|c|c|c}
\hline \multirow{2}{*}{ Sample } & \multicolumn{4}{|c}{$\mathbf{0 . 9 7}$} \\
\cline { 2 - 5 } & Ace & Chao 1 & Shannon & Simpson \\
\hline Monoculture alfalfa & $406.0 \pm 12.83 \mathrm{a}$ & $403.3 \pm 14.61 \mathrm{a}$ & $4.81 \pm 0.029 \mathrm{a}$ & $0.0181 \pm 0.0008 \mathrm{~b}$ \\
Alfalfa intercropping & $420.3 \pm 12.47 \mathrm{~b}$ & $439.3 \pm 25.84 \mathrm{~b}$ & $5.13 \pm 0.021 \mathrm{~b}$ & $0.0101 \pm 0.0003 \mathrm{a}$ \\
Monoculture wheat & $401.7 \pm 9.18 \mathrm{a}$ & $406.7 \pm 14.27 \mathrm{a}$ & $5.11 \pm 0.021 \mathrm{a}$ & $0.0104 \pm 0.0003 \mathrm{a}$ \\
Wheat intercropping & $449.3 \pm 10.34 \mathrm{~b}$ & $441.7 \pm 9.18 \mathrm{~b}$ & $5.27 \pm 0.025 \mathrm{~b}$ & $0.0093 \pm 0.0004 \mathrm{a}$ \\
\hline
\end{tabular}

\section{Distribution of taxa and phylotypes across 4 liberates}

The 49,394 classifiable sequences were affiliated with 9 bacterial phyla (Fig. A2). The groups accounted for $97.31 \%$ of all sequences, and a few sequences $(<1 \%)$ could not be shown. The dominant phyla were as follows: Proteobacteria, Acidobacteria, Bacteroidetes, Actinobacteria, Planctomycetes, Chloroflexi, and Nitrospirae, representing $42.60,25.10,8.93,4.92,4.73,4.15$ and $3.72 \%$, respectively, of all sequences that were classified below the domain level. These dominant bacterial phyla were shared in all samples (Table 2). Other sequences belonged to Firmicutes, Gemmatimonadetes and unclassified bacteria, and they were invariably found in very low proportions $(<2 \%)$. Proteobacteria accounting for $42.60 \%$ was the most dominant among the 9 phyla in all samples, regardless of the different samples. Acidobacteria was the second largest phylum in all groups accounting for $25.10 \%$. The other 7 phyla sequences accounting for 8.93-1.07\% (Fig. A2).

Comparative analysis of the 4 libraries revealed a distinct distribution of the bacterial phyla (Table 2). On average, Proteobacteria and Actinobacteria showed a higher relative abundance in alfalfa rhizosphere soils than in wheat rhizosphere soils, whereas Bacteroidetes and Chloroflexi showed the opposite pattern. The phyla of Actinobacteria, Acidobacteria, Proteobacteria, Bacteroidetes, Firmicutes, Bacteria_unclassified, Gemmatimonadetes and Nitrospirae were found in variable proportions, depending on the use of monoculture or intercropping; Most of Bacteroidetes, Bacteria_unclassified and Gemmatimonadetes were found in alfalfa intercropping libraries $(P<0.05)$, whereas Proteobacteria and Firmicutes were present at higher percentages in monoculture alfalfa libraries $(P<0.05)$. Moreover, the relative abundances of Actinobacteria and Firmicutes in wheat intercropping were significantly higher than that of monoculture wheat $(P<0.05)$, whereas Acidobacteria and Nitrospirae were present at higher percentages in monoculture wheat libraries $(P<0.05)$.

\section{Proteobacteria sequences}

The dominant phyla across all 4 libraries were Proteobacteria representing 42.60\%, which predominated in all 4 libraries and showed the greatest diversity. Four classes: $\alpha-$ Proteobacteria, $\beta$-Proteobacteria, $\delta$-Proteobacteria and $\gamma$-Proteobacteria, were affiliated with the Proteobacteria phylum (Fig. 2). The $\beta$-Proteobacteria sequences were most abundant, representing $41.00 \%$ of the Proteobacteria. The $\alpha$-Proteobacteria 
and $\gamma$-Proteobacteria were relatively abundant, representing 25.36 and $27.65 \%$ of the Proteobacteria, respectively. The $\gamma$-Proteobacteria sequences representing $5.99 \%$ of the Proteobacteria.

Table 2. Relative abundance of the phylogenetic groups presents in the monoculture and intercropping soils. Note: a one factor (niche) ANOVA (Duncan post-hoc test) was applied on the relative distribution values and results are presented in the column entitled

'statistics'. ns: non-significant differences. The phylogenetic groups for which a significant or nearly significantly effect of the niche are presented. AM > IA means significantly more present in the AM soil than in IA soil. AM < IA means significantly more present in the IA soil than in AM soil. WM > IM means significantly more present in the WM soil than in IM soil. WM < IM means significantly more present in the IM soil than in WM soil

\begin{tabular}{|c|c|c|c|c|c|c|c|c|c|c|c|c|c|c|}
\hline & \multicolumn{3}{|c|}{$\begin{array}{c}\text { Alfalfa } \\
\text { monoculture }\end{array}$} & \multicolumn{3}{|c|}{$\begin{array}{l}\text { Intercropping } \\
\text { alfalfa }\end{array}$} & \multirow[b]{2}{*}{ Statistics } & \multicolumn{3}{|c|}{$\begin{array}{c}\text { Wheat } \\
\text { monoculture }\end{array}$} & \multicolumn{3}{|c|}{$\begin{array}{c}\text { Intercropping } \\
\text { wheat }\end{array}$} & \multirow[b]{2}{*}{ Statistics } \\
\hline & AM1 & AM2 & AM3 & IA1 & IA2 & IA3 & & WM1 & WM2 & WM3 & IW1 & IW2 & IW3 & \\
\hline Proteobacteria & 51.02 & 50.13 & 47.05 & 37.64 & 42.94 & 40.98 & $\begin{array}{c}\text { AM }>\text { IA } \\
(P=0.0106)\end{array}$ & 42.02 & 46.19 & 39.60 & 43.20 & 44.23 & 41.98 & ns \\
\hline Acidobacteria & 18.93 & 22.38 & 23.69 & 21.99 & 25.66 & 26.99 & ns & 23.23 & 24.87 & 27.21 & 16.90 & 15.86 & 21.20 & $\begin{array}{c}\mathrm{WM}>\mathrm{IW} \\
(P=0.0237)\end{array}$ \\
\hline Actinobacteria & 8.99 & 6.69 & 6.99 & 8.94 & 9.12 & 10.47 & ns & 5.52 & 4.18 & 5.06 & 10.02 & 8.79 & 7.17 & $\begin{array}{l}\text { IW }>\text { WM } \\
(P=0.015)\end{array}$ \\
\hline Bacteroidetes & 2.89 & 3.56 & 3.78 & 8.13 & 5.79 & 5.83 & $\begin{array}{c}\mathrm{IA}>\mathrm{AM} \\
(P=0.0179)\end{array}$ & 10.57 & 7.46 & 8.76 & 6.37 & 7.29 & 7.04 & ns \\
\hline Chloroflexi & 2.96 & 3.43 & 3.47 & 4.76 & 3.02 & 3.35 & ns & 3.42 & 3.62 & 5.41 & 6.14 & 7.11 & 5.23 & ns \\
\hline Firmicutes & 5.63 & 6.29 & 6.95 & 2.53 & 1.86 & 1.76 & $\begin{array}{c}\text { AM }>\text { IA } \\
(P=0.0007)\end{array}$ & 1.78 & 1.58 & 1.47 & 5.02 & 4.14 & 3.89 & $\begin{array}{c}\mathrm{IW}>\mathrm{WM} \\
(P=0.0015)\end{array}$ \\
\hline Nitrospirae & 2.72 & 3.82 & 2.40 & 4.13 & 2.83 & 2.86 & ns & 4.00 & 3.55 & 3.62 & 2.03 & 2.18 & 3.01 & $\begin{array}{c}\mathrm{WM}>\mathrm{IW} \\
(P=0.0171)\end{array}$ \\
\hline Planctomycetes & 3.02 & 2.04 & 2.90 & 4.64 & 3.39 & 2.73 & $\mathrm{~ns}$ & 5.12 & 4.46 & 4.61 & 4.78 & 3.61 & 3.91 & ns \\
\hline Bacteria_unclassified & 0.23 & 0.27 & 0.32 & 3.45 & 2.67 & 2.46 & $\begin{array}{c}\mathrm{IA}>\mathrm{AM} \\
(P=0.001)\end{array}$ & 2.01 & 1.52 & 1.38 & 2.11 & 2.46 & 1.92 & ns \\
\hline Gemmatimonadetes & 1.60 & 1.01 & 1.02 & 2.48 & 1.94 & 1.85 & $\begin{array}{c}\mathrm{IA}>\mathrm{AM} \\
(P=0.0336)\end{array}$ & 1.41 & 1.51 & 1.69 & 1.39 & 1.42 & 1.82 & ns \\
\hline Others & 2.01 & 0.38 & 1.43 & 1.31 & 0.78 & 0.72 & ns & 0.92 & 1.06 & 1.19 & 2.04 & 2.91 & 2.83 & $\begin{array}{c}\mathrm{IW}>\mathrm{WM} \\
(P=0.006)\end{array}$ \\
\hline
\end{tabular}

The $\alpha$-Proteobacteria were relatively abundant and diversity. 5 orders were identified as being related to $\alpha$-Proteobacteria (Fig. 2A). The Rhizobiales was the most abundant order in 4 libraries, representing $63.47 \%$. The relatively abundant orders affiliated to $\alpha$-Proteobacteria were Caulobacterales, Rhodospirillales, Richettsiales and Sphingomonadals, representing 9.82,11.42, 0.03 and 15.25\%. Depending on the use of monoculture and intercropping, most of Rhizobiales and Rhodospirillales were found in intercropping alfalfa, whereas low abundance was found in intercropping wheat $(P<0.05)$. Sphingomonadals showed a contrary variation, presenting at higher abundances in intercropping wheat and lower abundances in intercropping alfalfa comparing with monoculture $(P<0.05)$, respectively. The comparison of relative abundances of Caulobacterales revealed no significant differences between intercropping and monoculture libraries $(P>0.05)$. 1 OTU was related to Richettsiales and identified in alfalfa monoculture libraries only.

The $\beta$-Proteobacteria were most abundant and diversity in 4 libraries. 8 orders were identified as being related to $\beta$-Proteobacteria (Fig. $2 B$ ). The Burkholderiales was the most abundant order in 4 libraries, representing $65.60 \%$. The relatively abundant orders 
affiliated to $\beta$-Proteobacteria were Nitrosomonadales, SC-I-84 and Methylophilales, representing 13.91, 13.78 and $1.77 \%$. Depending on the use of monoculture and intercropping, most of Burkholderiales and Methylophilale were found in monoculture libraries (WM and AM) $(P<0.05)$, whereas Beraproteobacteria_unclassified, Nitrosomonadales and SC-I-84 were present at higher abundances in intercropping alfalfa compared with monoculture alfalfa $(P<0.05)$. The comparison of relative abundances of TRA3-2 revealed no significant differences between intercropping and monoculture libraries $(P>0.05) .95$ and 2 OTUs were related to Hydrogenophilale and B1-7BS, respectively, while Hydrogenophilale appeared in intercropping wheat libraries only and B1-7BS in alfalfa monoculture and wheat monoculture libraries.
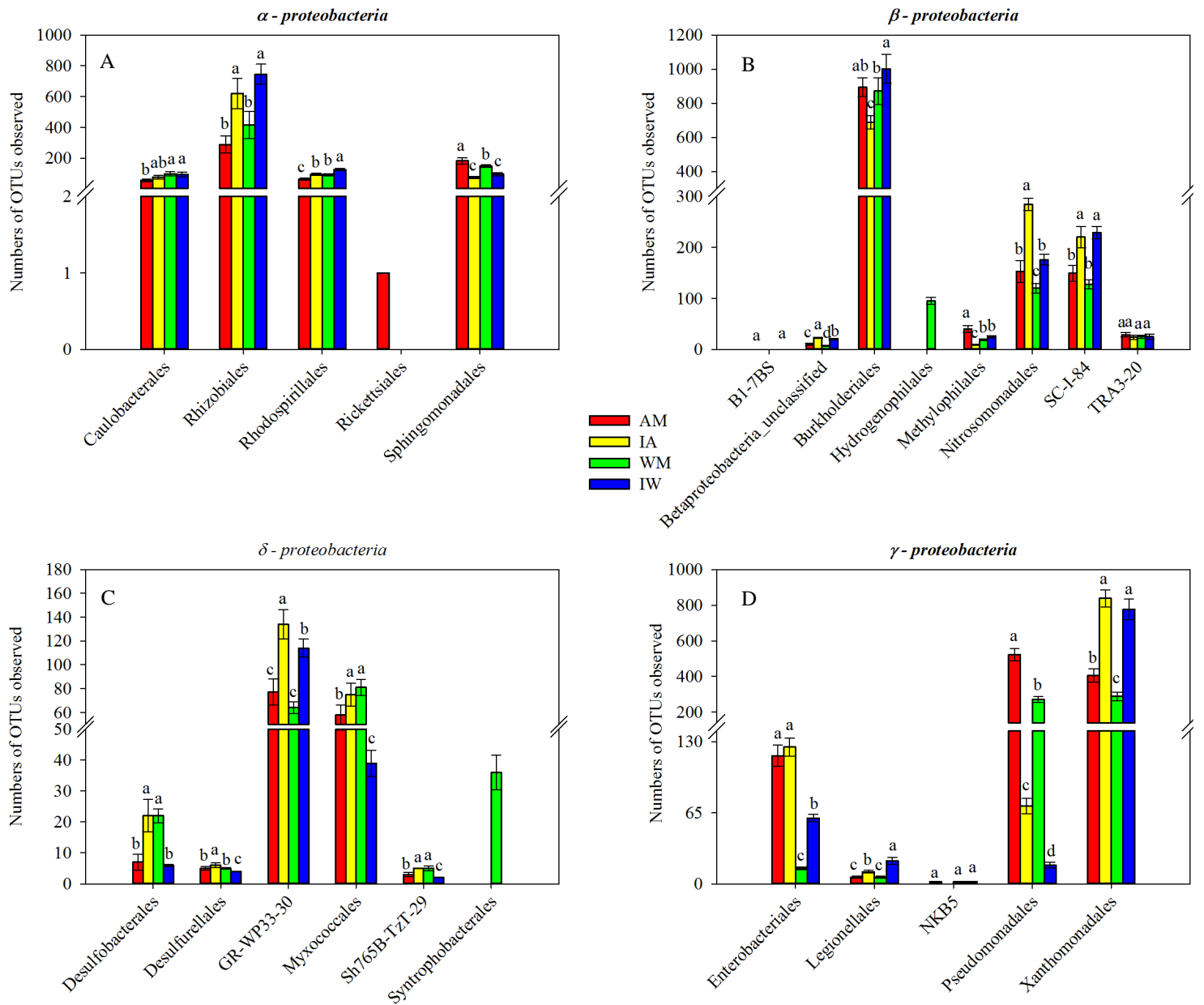

Figure 2. Numbers of OTUs of Proteobacteria orders in 4 libraries. The significant differences between the means were determined using Duncan post-hoc test

The $\delta$-Proteobacteria were relatively abundant and diversity. 6 orders were identified as being related to $\delta$-Proteobacteria (Fig. 2C). The GR-WP33-30 was the most abundant order in 4 libraries, representing $50.52 \%$, with a relative abundance in intercropping alfalfa higher compared to corresponding monoculture alfalfa, whereas GR-WP33-30 was present at lower relatively abundances in intercropping wheat. The relatively abundant orders affiliated to $\delta$-Proteobacteria were Desulfobacterales and Myxococcales, representing 7.40 and $32.86 \%$. Depending on the use of monoculture and 
intercropping, most of Desulfobacterales, Desulfurellales, Myxococcales and Sh765B$T z T-29$ were found in intercropping alfalfa libraries $(P<0.05)$, whereas low abundance was found in intercropping wheat libraries $(P<0.05)$. 36 OTUs was related to Syntrophobacterales and identified in intercropping wheat libraries only.

The $\gamma$-Proteobacteria were relatively abundant and diversity. 5 orders were identified as being related to $\gamma$-Proteobacteria (Fig. 2D). The Xanthomonadales was the most abundant order in 5 libraries, representing $64.93 \%$, with a relative abundance in intercropping alfalfa higher compared to corresponding monoculture alfalfa, whereas Xanthomonadales was present at lower relatively abundances in intercropping wheat. The relatively abundant orders affiliated to $\gamma$-Proteobacteria were Pseudomonadales, Enterobacteriales, Legionllales and NKB5 representing $24.77,8.89,1.24$ and $0.17 \%$. Depending on the use of monoculture and intercropping, most of Pseudomonadales were found in monoculture libraries $(P<0.05)$. The comparison of relative abundances of Enterobacteriales and NKB5 revealed no significant differences between intercropping and monoculture alfalfa $(P>0.05)$, whereas Enterobacteriales and Legionllales was present at higher abundances in intercropping wheat $(P<0.05)$. 6 OTUs was related to NKB5 and appeared in AM, IW, WM libraries, respectively.

\section{Acidobacteria sequences}

$25.10 \%$ of the total clones were affiliated with the Acidobacteria phylum. These sequences were affiliated with 10 orders of Acidobacteriales, Subgroup 3, 4, 5, 6, 7, 10 , 11, 17, 25 and no rank Acidobacteria (Fig. 3). The Subgroup 6, 4 and 3 were the most abundant order in 4 libraries, representing 66.01, 18.93 and $6.95 \%$, respectively. The relative abundances of Subgroup 3 and 6 in intercropping alfalfa were higher than monoculture alfalfa $(P<0.05)$. A similar trend was also found by comparison of intercropping and monoculture wheat. In addition, sequences affiliated to Subgroup 5, 7, 17 and 25 were relatively abundant order in 4 libraries. The comparison of relative abundances of Subgroup 5 revealed no significant differences between intercropping and monoculture libraries $(P>0.05)$. We observed higher relative abundances of Subgroup 7 in intercropping libraries compared to corresponding monoculture libraries $(P<0.05)$. Depending on the use of monoculture and intercropping, most of Subgroup 17 was found in intercropping alfalfa libraries, and high abundance of Subgroup 25 was found in intercropping wheat libraries $(P<0.05)$. The abundance of Subgroup 10, 11, Acidobacteriales and no rank Acidobacteria were low, representing 0.80, 0.19, 0.30 and $0.42 \%$.

\section{Sequences of other relatively abundant groups}

The Bacteroidetes were relatively abundant and diversity, accounting for $8.93 \%$ of the analyzed OTUs. These OTUs were affiliated with 4 orders of Cytophagales, Flavobacteriales, Sphingobacteriales and VadinHA17_norank (Fig. 4). The relatively abundances of Cytophagales in intercropping libraries were higher than monoculture, while Flavobacteriales and Sphingobacteriales in intercropping alfalfa were higher than monoculture. In addition, 80 OTUs was related to VadinHA17_norank and identified in IW libraries only.

The Actinobacteria had most abundant orders, affiliated with 11 orders of Acidimicrobiales, Corynebacteriales, Frankiales, Gaiellales, Micrococcales, 
Micromonosporales, Propionibacteriales, Pseudonocardiales, Solirubrobacteriales, Streptomycetales and Actinobacteria_norank (Fig. 4). The relatively abundances of Acidimicrobiales, Frankiales, Gaiellales, Propionibacteriale and Solirubrobacteriales in intercropping libraries were higher than monoculture.

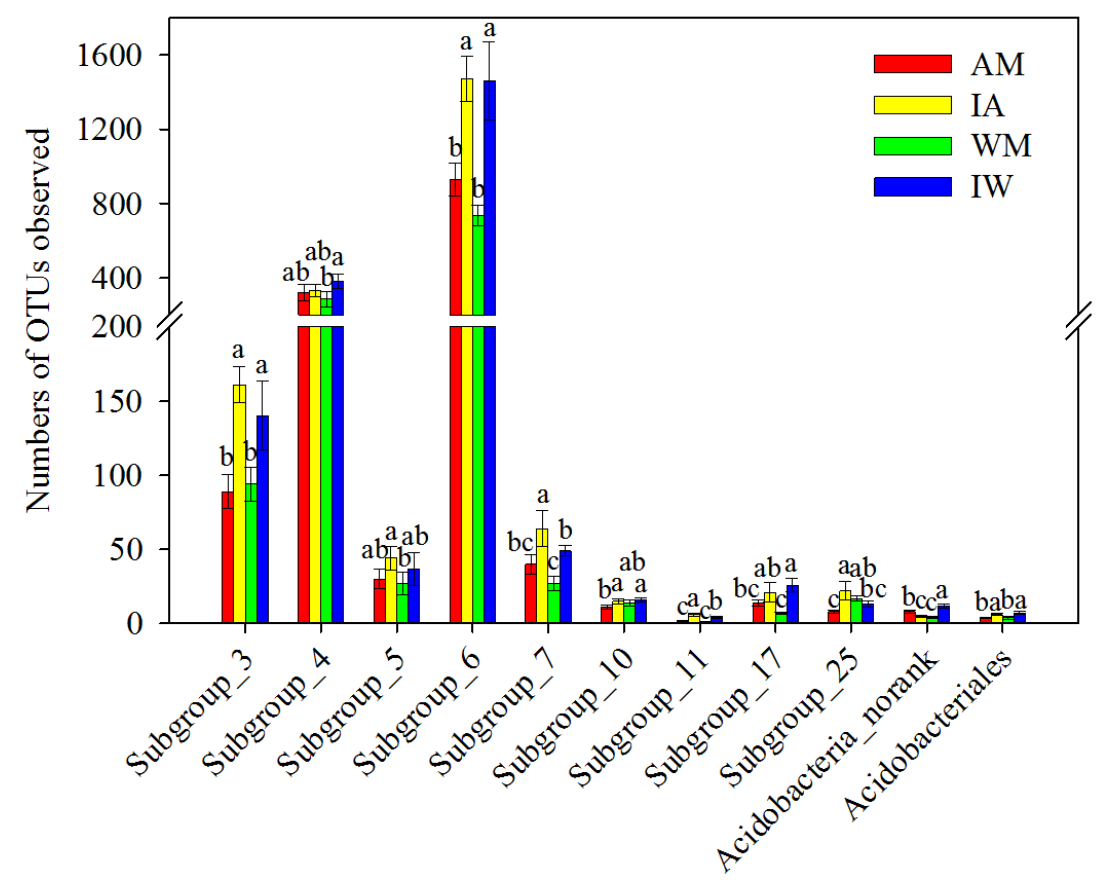

Figure 3. Numbers of OTUs of Acidobacteria orders in 4 libraries. The significant differences between the means were determined using Duncan post-hoc test

In addition, some orders affiliated to other phylum had significant differences between intercropping and monoculture libraries. Such as Anaerolineales, Caldilineales, Clostridiales (affiliated to Chlorofiexi) and Lactobacillales (affiliated to Fimicutes) showed a higher relative abundance in intercropping libraries compared with monoculture libraries, regardless of plant species (Fig. 4). Whereas, depending on the use of monoculture and intercropping, Bacillus (affiliated to Fimicutes) was present at higher relatively abundances in intercropping alfalfa only.

\section{Shared bacterial OTUs}

Venn diagrams revealed that the sum of total observed OTUs in the four soil samples was 475 (Fig. 5), and 307 OTUs were shared all of the soil samples. Moreover, the distribution of sequences demonstrated once again that each plant rhizosphere had its own microbial population.

\section{PCA analysis}

This was supported by the principal component analysis (PCA) with the weighted Unifrac distance (Fig. 6). Overall, the two PCA axes explained $81.41 \%$ of the variation between the different communities. The PCA score plot revealed that intercropping patterns significantly change bacterial communities in wheat and alfalfa rhizosphere soils. The intercropping (IA and IW) soil microbiota clustered separately from the 


$$
-4497 \text { - }
$$

microbiota of the monoculture (AM and WM) soils along principal components 1 (Fig. 6), suggesting that the application of intercropping pattern influenced the population structure of the soil bacteria.
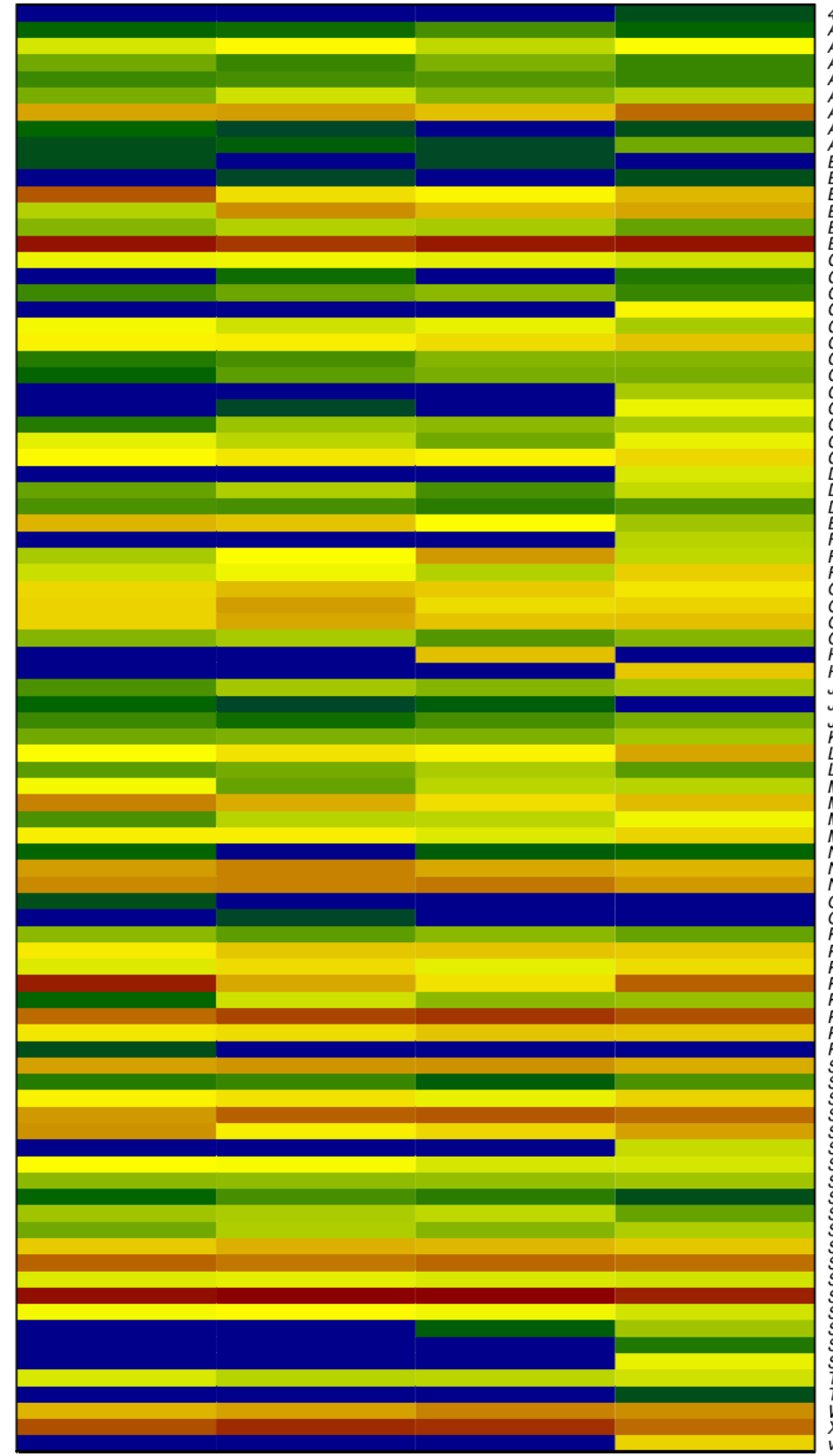

AM $\quad$ IA

WM

IW
$43 F-1404 R$

AT425-EubC11 terrestrial group

Acidobacteria norank

Acidobacteriales

Antinobacteria norank

Ardenticatenia uncultured

Armatimonadetes_norank

BD2-11_terrestrial_group

Bacteria unclassified

Betaproteobacteria_unclassified

Burkholderiales

Caldilineales

Candidate division BRC1 norank

Candidate division OP8 norank

Candidate_division_WS3_norank

Caulobacterales

Chloroflexales

Chloroflexi_unclassified

Clostridiales

Cyanobacteria norank

Deltaproteobacteria deltaproteobacteria incertae si Desulfobacterales

Desulfurellales

Enterobacteriales
FS $117-23 B-02$

Flavobacteriales

Frankiales

GR-WP33-30

Gaiellales

Gitt-GS -136 noran

Herpetosiphonales

Hydrogenophilales

G30-KF-CM66 norank

IL-ETNP-Z39 norank

KD4-96 norank
Lactobacillales

Legionellales

Methylophilales

Micromonosporales

Myxococcales

NKB5

Nitrosomonadales

Nitrospira_norank
OM190 norank

Opitutales

P2-11E norank

Planctomycetales

Propionibacteriales

Pseudonocardiales

Rhizobiales

Rhodospirillales

Rickettsiales

Sh765B-TzT-29

Solirubrobacterales

Sphingobacteriales

Sphingomonadales

Streptomycetales

Subgroup 10

Subgroup 11

Subgroup_ 17

Subrroup 3

Subgroup 4

Subgroup 5

Subgroup 6

Subsection III

Synergistales

Syntrophobacterales

TRA3-20

Thermotogales

WD2101_soil group

vadinHA17 norank

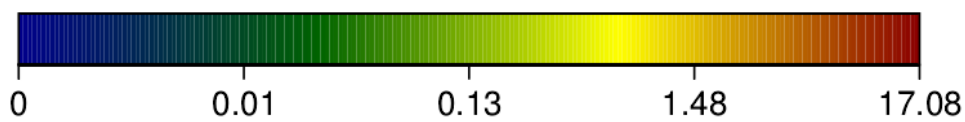

Relative abundance of community (\%)

Figure 4. Hierarchical cluster analysis of predominant orders among the 4 libraries. The color intensity of scale indicates relative abundance of each OTU read. Relative abundance was defined as the number of sequences affiliated with that OTU divided by the total number of 


$$
-4498 \text { - }
$$

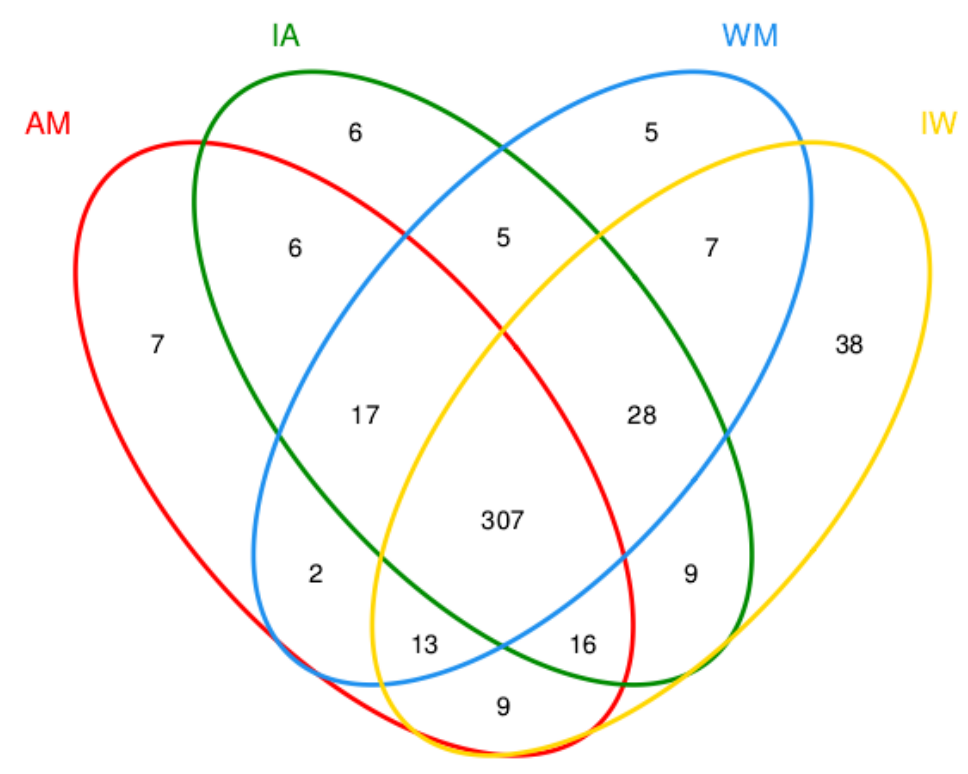

Figure 5. Venn diagram showing the shared bacterial OTUs (at a distance of 0.03) in 4 soil samples. Alfalfa monoculture (AM), intercropping alfalfa (IA), wheat monoculture (WM), and intercropping wheat $(I W)$

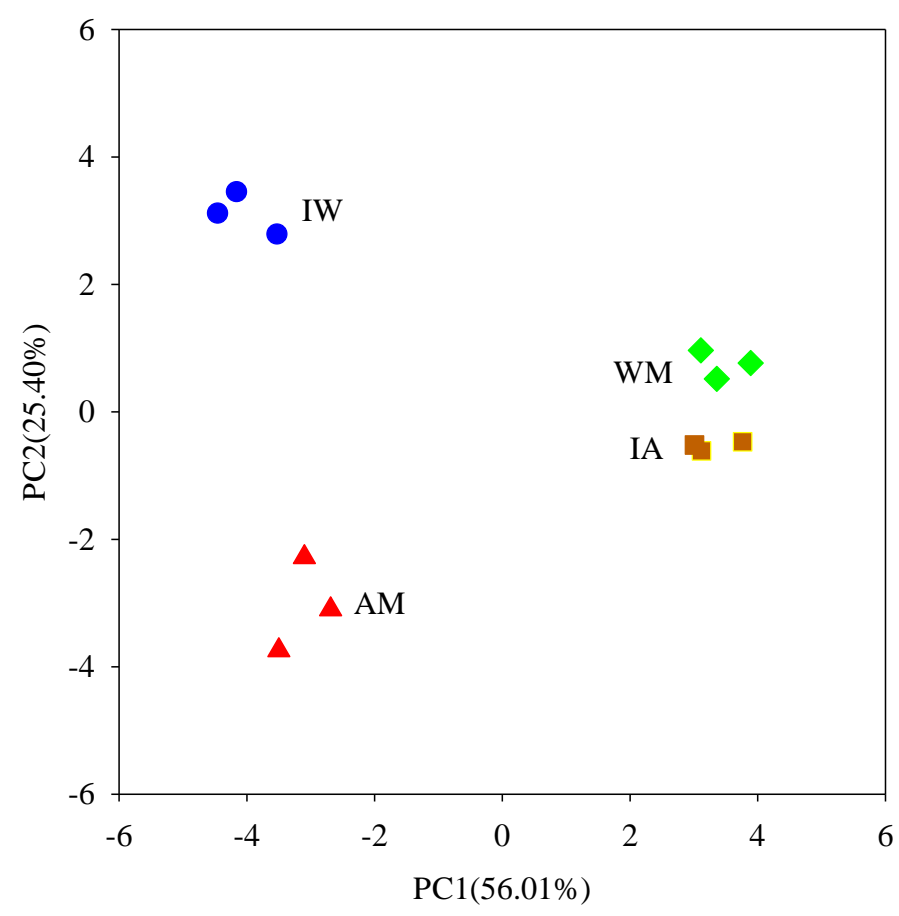

Figure 6. Principal component analysis (PCA) of bacterial communities from Alfalfa monoculture (AM), intercropping alfalfa (IA), wheat monoculture (WM), and intercropping wheat (IW) based on pyrosequencing of the $16 \mathrm{~S}$ rDNA gene. PCA were generated using the presence of each OTU (at a distance level of 3\%) found in each clone library. Principal components (PCs) 1 and 2 explained $56.01 \%$ and $25.40 \%$ of the variance, respectively 


\section{Discussion}

In this study, 16S rDNA gene clone library analyses were undertaken to study soil bacterial communities in wheat-alfalfa intercropping systems. A single study refers to cereal-legume intercropping, dominantly focusing on soil cultivable microbial flora (Chai et al., 2004). But data on overall bacterial communities living in cereal and legume roots vicinity are still lacking. To our knowledge, this study is the first to report data concerning the uncultivable microbial flora surrounding wheat and alfalfa in monoculture and intercropping systems, respectively. It is known that a wide range of factors influences soil bacterial communities. Soil type, plant species and cropping patterns are the reasons that most affect the bacterial communities in soils (Igwe Vannette, 2019; Rui et al., 2015). Shannon diversity analyses revealed a richer bacterial community in intercropping soil than that of monoculture (Table 1). This observation may be supported by PCA result that demonstrates that soil bacterial communities obtained from monoculture and intercropping system were different, regardless of plant species (Fig. 6). The result demonstrated bacterial communities in rhizosphere soils were indeed affected by intercropping patterns. The presence of alfalfa plants contributed to attenuate eventual bacterial community variations occurring in intercropping wheat. Indeed, legume-based intercropping systems present a more heterogeneous vegetation cover, a patchier distribution of plant litter and rooting patterns that can affect soil properties and microbial communities (Lacombe et al., 2009; Reynolds et al., 2007). The result demonstrated bacterial communities in rhizosphere soils were indeed affected by intercropping patterns. Moreover, an influence of plant species on bacterial diversity was observed.

The high diversity of soil bacteria in intercropping and monoculture systems were shown based on the sequence analyses. For microbial analysis of soil, the dominant taxonomic groups were Proteobacteria, Acidobacteria, Bacteroidetes, Actinobacteria, Planctomycetes, Chloroflexi, and Nitrospirae (Fig. A2). These phyla have been described as common inhabitants of farmland soils ( $\mathrm{Li}$ et al., 2016, 2020). The diversity of Actinobacteria and Bacteroidetes were relatively abundant in 4 libraries and present at higher percentages in intercropping libraries. Additionally, some phylum that were not abundant in these libraries, including Gemmatimonadetes and Bacteria_unclassified, showed higher percentages in intercropping alfalfa soils $(P<0.05)$, which indicated an important role of intercropping in shaping the soil microbial communities. Other phylotypes showed the opposite variation in monoculture and intercropping system. The diversity of Acidobacteria and Nitrospirae were relatively abundant in 4 libraries and present at higher percentages in monoculture wheat libraries $(P<0.05)$. In addition, Firmicutes showed higher percentages in monoculture alfalfa soils. There were another two different changes including bacterial populations absent or appeared only in monoculture libraries, whereas the phylotypes of Syntrophobacterales and Hydrogenophilale appeared only in intercropping libraries.

Most of previous studies have indicated that legume and cereal intercropping is profitable for increasing crop yield ( $\mathrm{Li}$ et al., 2007). In our research, the yield data clearly demonstrates the superiority of the use of intercropping pattern (Fig. 1). This beneficial effect may be attributed to the maintenance and improvement of microbial activity and community composition (Fu et al., 2018). Two main mechanisms that soil microbes affect plant productivity can be distinguished: direct effects on plants by means of root-associated organisms that form mutualistic or pathogenic relationships with plants, and indirect effects by means of the action of free-living microbes that 
change rates of nutrient supply and the partitioning of resources (Van Der Heijden et al., 2008). In our study, the complex changes of bacterial community diversity and abundant identified in monoculture and intercropping libraries raises one question. What relationship did the changing bacterial population and increasing of crop yield in intercropping pattern? Soil nutrition (eg. nitrogen, phosphorus and potassium or some other non-N nutrient that is limiting in a habitat) limits plant productivity (Chapin III, 1980), which showed plant-soil feedback processes are also dominating. Beneficial plant rhizobacteria are associated with the surfaces of plant roots and may increase plant yield via mechanisms that improved mineral nutrient uptake, disease suppression, or phytohormone production (Sameh and Youseif, 2018; Sood et al., 2018; Hokkanen and Lynch, 1995). Legumes and nonlegumes can "complement" each other in the use of $\mathrm{N}$ sources since both the legume and nonlegume utilize soil inorganic $\mathrm{N}$ sources, but nodule in leguminous plants can also fix atmospheric $\mathrm{N}_{2}$ in symbiosis with Rhizobiales (Jensen, 1996a, b). Wheat intercropping libraries had more Rhizobiales than wheat monoculture libraries (Fig. 2). The amount of soil nitrogen-fixing bacteria in alfalfa intercropping soils increased mainly in the presence of wheat. Previous studies also confirm that $\mathrm{N}_{2}$ fixation of legumes may be improved by intercropping when the no legume is a strong competitor for soil inorganic N (Giller et al., 1991; KarpensteinMachan et al., 2000; Hauggaard-Nielsen et al., 2001).

The recent studies of overyielding in agriculture intercropping systems found a important mechanism underlying such facilitation is the ability of some crop species to chemically mobilize otherwise-unavailable forms of one or more limiting soil nutrients such as phosphorus ( $\mathrm{Li}$ et al., 2014). Plant do not take up organic P directly, rather, organic $\mathrm{P}$ is first hydrolyzed by microbial or root-related phosphatases. Therefore, phosphate solubilizing bacteria have a important role in soils with low concentration of available phosphorus. Phosphate solubilizing bacteria were present in different proportions in monoculture and intercropping soils. Burkholderiales and Pseudomonadales were more abundance in intercropping soils than that monoculture soils. These bacteria can improve solubilization of fixed soil phosphorus and applied phosphates resulting in higher crop yields (Nautiyal, 1999). Moreover, Actinobacteria have a critical role in decomposition of soil organic materials, such as cellulose and chitin (Sykes et al., 1973). Actinobacteria of intercropping soils were higher than that of monoculture soils, which may be due to the presence of more organic matter used by plants in intercropping soils. Compared with monoculture, the number of organic acid in the roots exudates was increased in wheat/maize intercropping (Hao et al., 2003), which might affect some acid-sensitive microbes. Acidobacteria of intercropping alfalfa soils were higher than that of monouculture soils, which may be due to the presence of more organic matter used by plants in intercropping soils. Acidobacteria are capable of degradation of plant litter in soils (Eichorst et al., 2011), the presence of wheat debris in monoculture samples and alfalfa root exudates and litter in intercropping samples may have contributed to the observed differences.

Another route by which soil microbes affect plant productivity is disease suppression, as an example through the production of antifungal metabolites (Weller et al., 2002). Plants release enormous of chemicals through their roots, at a significant carbon cost, to combat pathogenic microorganisms and attract beneficial ones (Badri et al., 2009). The activity and effects of beneficial rhizosphere microorganisms on plant growth and health are well documented for bacteria like by Pseudomonales and Burkholdera (Badri et al., 2009). Pseudomonales and Burkholderiales were present at 
higher relatively abundances in intercropping alfalfa and wheat, respectively. These bacteria protect several major agricultural crops against disease phenomenon that is likely to be also important in natural ecosystems (Van Der Heijden et al., 2008). Moreover, it is reported Bacillus also was major antagonists (Yuan et al., 2016), which can promote plant growth, protect against fungal pathogen attack (Asaka and Shoda, 1996), and play a role in the degradation of organic polymers in the soil (Emmert and Handelsman, 1999). Similar as Pseudomonales, Bacillus was present at higher relatively abundances in intercropping alfalfa. There are four main groups of plant pathogens, but only fungi and nematodes are major players in the soil (Hilbig and Allen, 2019). The structure and function of other plant pathogens also need further discovery. Consequently, the analyses of bacterial communities in our study can provided general information about the relationships between soil bacterial communities and intercropping patterns. Many of bacterial populations identified in 4 libraries showed significant differences between monoculture and intercropping systems, but only a few have been reported as being able to improve plant productivity and the functions of other populations also still await discovery.

\section{Conclusion}

Intercropping pattern improve crop productivity in the field. Our findings indicated that intercropping is a determinant in shaping bacterial community in soils. Intercropping led to variations in the plant-growth promoting rhizobactertia in the rhizosphere of wheat and alfalfa. The resulting microbial community is likely to be a mixture of the species-specific. The results provide a strong evidence for improving the microbial diversity of rhizosphere soil and the nutrients of rhizosphere soil in wheat/alfalfa intercropping, and provide a direction for further research on the role of specific microorganisms. The reason of the yield advantage of intercropping system caused by the change of crop rhizosphere microbial community structure needs further study.

Acknowledgements. The study was supported by the National Natural Science Foundation of China (41701289) and (C030301), China Postdoctoral Science Foundation (2018M640287).

\section{REFERENCES}

[1] Asaka, O., Shoda, M. (1996): Biocontrol of Rhizoctonia solani damping-off of tomato with Bacillus subtilis RB14. - Applied Environmental Microbiology 62: 4081-4085.

[2] Badri, D. V., Weir, T. L., Lelie, D. V. D., Vivanco, J. M. (2009): Rhizosphere chemical dialogues: plant-microbe interactions. - Current Opinion Biotechnology 20(6): 642-650.

[3] Bhatti, I. H., Ahmad, R., Jabbar, A., Nazir, M., Mahmood, T. (2006): Competitive behaviour of component crops in different sesame-legume intercropping systems. International Journal of Agriculture and Biology (Pakistan) 8(2): 165-167.

[4] Chai, Q., Huang, P., Huang, G. (2004): Effect of intercropping on soil microbial and enzyme activity in the rhizosphere. - Acta Prataculturae Sinica 14: 105-110.

[5] Chapin III, F. S. (1980): The mineral nutrition of wild plants. - Annual Review of Ecology Systematics 11(1): 233-260. 
[6] Choudhary, V. K., Kumar, P. S. (2016): Productivity, water use and energy profitability of staggered maize-legume intercropping in the eastern Himalayan region of India. Proceedings of the National Academy of Sciences India 86(3): 547-557.

[7] Du, W., He, X., Hu, Z., Zia, S., Muller, J. (2011): Effect of different irrigation technology on production of winter wheat. - Journal of drainage and irrigation machinery engineering 29(2): 170-174.

[8] Eichorst, S. A., Kuske, C. R., Schmidt, T. M. (2011): Influence of plant polymers on the distribution and cultivation of bacteria in the phylum Acidobacteria. - Applied Environmental Microbiology 77(2): 586-596.

[9] Emmert, E. A., Handelsman, J. (1999): Biocontrol of plant disease: a (Gram-) positive perspective. - Fems Microbiology Letters 171: 1-9.

[10] Giller, K. E., Wilson, K. J. (1991): Nitrogen Fixation in Tropical Cropping Systems. CAB Int., Wallingford.

[11] Hanming, H., Lei, Y., Zhao, L. H., Han, W., Fan, L. M., Yong, X., Zhu, Y. Y., Li, C. Y. (2012): The temporal-spatial distribution of light intensity in maize and soybean intercropping systems. - Journal of Resources and Ecology 3(2): 169-173.

[12] Hao, Y., Lao, X., Sun, W., Peng, S. (2003): Interaction of roots and rhizosphere in the wheat/maize intercropping system. - Rural Eco-Environment 19(4): 18-22.

[13] Hauggaard-Nielsen, H., Ambus, P., Jensen, E. S. (2001): Interspecific competition, N use and interference with weeds in pea-barley intercropping. - Field Crops Research 70(2): 101-109.

[14] Heijden, M. G. A. V. D., Bardgett, R. D., Straalen, N. M. V. (2008): The unseen majority: soil microbes as drivers of plant diversity and productivity in terrestrial ecosystems. - Ecology Letters 11(3): 296-310.

[15] Hesler, L. S., Kieckhefer, R. W. (2018): Wheat stem maggot in spring wheat-alfalfa intercrops with different crop management intensities. - Great Lakes Entomologist 33(1): 33-39.

[16] Hilbig, B. E., Allen, E. B. (2019): Fungal pathogens and arbuscular mycorrhizal fungi of abandoned agricultural fields: potential limits to restoration. - Invasive Plant Science and Management 12(3): 186-193.

[17] Hokkanen, H., Lynch, J. (1995): Benefits and Risks of Introducing Biocontrol Agents. Plant and Microbial Biotechnology Series, Cambridge University Press, Cambridge, UK.

[18] Igwe, A. N., Vannette, R. L. (2019): Bacterial communities differ between plant species and soil type, and differentially influence seedling establishment on serpentine soils. Plant \& Soil 441: 423-437.

[19] Jensen, E. (1996): Barley uptake of $N$ deposited in the rhizosphere of associated field pea. - Soil Biology and Biochemistry 28(2): 159-168.

[20] Jensen, E. S. (1996): Grain yield, symbiotic N2 fixation and interspecific competition for inorganic N in pea-barley intercrops. - Plant \& Soil 182: 25-38.

[21] Karpenstein-Machan, M., Stuelpnagel, R. (2000): Biomass yield and nitrogen fixation of legumes monocropped and intercropped with rye and rotation effects on a subsequent maize crop. - Plant \& Soil 218(1-2): 215-232.

[22] Kowalchuk, G. A., Stephen, J. R. (2001): Ammonia-oxidizing bacteria: a model for molecular microbial ecology. - Annual Reviews in Microbiology 55: 485-529.

[23] Lacombe, S., Bradley, R. L., Hamel, C., Beaulieu, C. (2009): Do tree-based intercropping systems increase the diversity and stability of soil microbial communities? - Agriculture, Ecosystems \& Environment 131(1): 25-31.

[24] Li, J., Huang, B., Wang, Q. X., Li, Y., Fang, W. S., Han, D. W., Yan, D. D., Guo, M. X., Cao, A. C. (2017): Effects of fumigation with metam-sodium on soil microbial biomass, respiration, nitrogen transformation, bacterial community diversity and genes encoding key enzymes involved in nitrogen cycling. - Science of the Total Environment 598(15): 1027-1036. 
[25] Li, L., Li, S. M., Sun, J. H., Zhou, L. L., Bao, X. G., Zhang, H. G., Zhang, F. S. (2007): Diversity enhances agricultural productivity via rhizosphere phosphorus facilitation on phosphorus-deficient soils. - Proceedings of the National Academy of Sciences 104(27): 11192-11196.

[26] Li, L., Tilman, D., Lambers, H., Zhang, F. S. (2014): Plant diversity and overyielding: insights from belowground facilitation of intercropping in agriculture. - New Phytologist 203(1): 63-69.

[27] Li, R., Liu, Y., Chu, G. X. (2015): Effects of different cropping patterns on soil enzyme activities and soil microbial community diversity in oasis farmland. - Chinese Journal of Applied Ecology 26(2): 490-496.

[28] Li, X., Sun, M., Zhang, H., Xu, N., Sun, G. (2016): Use of mulberry-soybean intercropping in salt-alkali soil impacts the diversity of the soil bacterial community. Microbial Biotechnology 9(3): 293-304.

[29] Li, X., Zhang, H. H., Sun, M. L., Xu, N., Sun, G. Y., Zhao, M. C. (2020): Land use change from upland to paddy field in Mollisols drives soil aggregation and associated microbial communities. - Applied Soil Ecology 146: 103351.

[30] Ma, X. L., Zhu, Q. L., Geng, C. X., Lu, Z. G., Long, G. Q., Tang, L. (2017): Contribution of nutrient uptake and utilization on yield advantage in maize and potato intercropping under different nitrogen application rates. The Journal of Applied Ecology 28(4): 1265.

[31] Morris, R., Garrity, D. (1993): Resource capture and utilization in intercropping; nonnitrogen nutrients. - Field Crops Research 34: 319-334.

[32] Nazih, N., Finlay-Moore, O., Hartel, P., Fuhrmann, J. (2001): Whole soil fatty acid methyl ester (FAME) profiles of early soybean rhizosphere as affected by temperature and matric water potential. - Soil Biology and Biochemistry 33(4): 693-696.

[33] Ren, Y. Y., Wang, X. L., Zhang, S. Q., Palta, J. A., Chen, Y. L. (2017): Influence of spatial arrangement in maize-soybean intercropping on root growth and water use efficiency. - Plant \& Soil 415(1-2): 131-144.

[34] Reynolds, P. E., Simpson, J. A., Thevathasan, N. V., Gordon, A. M. (2007): Effects of tree competition on corn and soybean photosynthesis, growth, and yield in a temperate tree-based agroforestry intercropping system in southern Ontario, Canada. - Ecological Engineering 29: 362-371.

[35] Rillig, M. C., Mummey, D. L. (2006): Mycorrhizas and soil structure. - New Phytologist 171: 41-53.

[36] Schimel, J. P., Schaeffer, S. M. (2012): Microbial control over carbon cycling in soil. Frontiers in Microbiology 3: 348.

[37] Singleton, D. R., Furlong, M. A., Rathbun, S. L., Whitman, W. B. (2001): Quantitative comparisons of $16 \mathrm{~S}$ rRNA gene sequence libraries from environmental samples. Applied Environmental Microbiology 67(9): 4374-4376.

[38] Skelton, L. E., Barrett, G. W. (2005): A comparison of conventional and alternative agroecosystems using alfalfa (Medicago sativa) and winter wheat (Triticum aestivum). Renewable Agriculture and Food Systems 20(1): 38-47.

[39] Song, Y., Zhang, F., Marschner, P., Fan, F., Gao, H., Bao, X., Sun, J., Li, L. (2007): Effect of intercropping on crop yield and chemical and microbiological properties in rhizosphere of wheat (Triticum aestivum L.), maize (Zea mays L.), and faba bean (Vicia faba L.). - Biology and Fertility of Soils 43(5): 565-574.

[40] Sood, G., Kaushal, R., Chauhan, A., Gupta, S. (2018): Indigenous plant-growthpromoting rhizobacteria and chemical fertilisers: impact on wheat (Triticum aestivum) productivity and soil properties in North Western Himalayan region. - Crop \& Pasture Science 69(5): 460-468.

[41] Su, C., Lei, L., Duan, Y., Zhang, K. Q., Yang, J. (2012): Culture-independent methods for studying environmental microorganisms: methods, application, and perspective. Applied Microbiology and Biotechnology 93(3): 993-1003. 
[42] Vandermeer, J. (1995): The ecological basis of alternative agriculture. - Annual Review of Ecology and Systematics 26(1): 201-224.

[43] Vandermeer, J. H. (1992): The Ecology of Intercropping. - Cambridge University Press.

[44] Vrignon-Brenas, S., Celette, F., Piquet, A., Corre, G., David, C. (2018): Intercropping strategies of white clover with organic wheat to improve the trade-off between wheat yield, protein content and the provision of ecological services by white clover. - Field Crops Research 224(1): 160-169.

[45] Wang, Y., Yuan, Y. H., Liu, B., Zhang, Z. W., Yue, T. L. (2016): Biocontrol activity and patulin-removal effects of Bacillus subtilis, Rhodobacter sphaeroides and Agrobacterium tumefaciens against Penicillium expansum. - Journal of Applied Microbiology 121(5): 1384-1393.

[46] Wardle, D. A., Bardgett, R. D., Klironomos, J. N., Setälä, H., Putten, V. D. W. H., Wall, D. H. (2004): Ecological linkages between aboveground and belowground biota. Science 304(5677): 1629-1633.

[47] Weller, D. M., Raaijmakers, J. M., Gardener, B. B. M., Thomashow, L. S. (2002): Microbial populations responsible for specific soil suppressiveness to plant pathogens 1 . - Annual Review of Phytopathology 40: 309-348.

[48] Willey, R. (1999): Intercropping - its importance and research needs. Part 1. Competition and yield advantages. - Field Crop Abstracts 32: 1-10.

[49] Yan, F., Schubert, S., Mengel, K. (1996): Soil pH changes during legume growth and application of plant material. - Biology and Fertility of Soils 23(3): 236-242.

[50] Youseif, S. H. (2018): Genetic diversity of plant growth promoting rhizobacteria and their effects on the growth of maize plants under greenhouse conditions. - Annals of Agricultural Sciences 63(1).

[51] Yue, L., Charles, F., Pute, W., Xiao, L. C. (2014): Maize-soybean intercropping interactions above and below ground. - Crop Science 54(3): 914-920.

[52] Zarraonaindia, I., Smith, D. P., Gilbert, J. A. (2013): Beyond the genome: communitylevel analysis of the microbial world. - Biology Philosophy 28(2): 261-282.

[53] Zhi-dan, F. U., Zhou, L., Chen, P., Du, Q., Pang, T., Song, C., Wang, X. C., Liu, W. G., Yang, W. Y., Yong, T. W. (2019): Effects of maize-soybean relay intercropping on crop nutrient uptake and soil bacterial community. - Journal of Integrative Agriculture 18(9): 2006-2018.

[54] Zhou, X., Yu, G., Wu, F. (2011): Effects of intercropping cucumber with onion or garlic on soil enzyme activities, microbial communities and cucumber yield. - European Journal of Soil Biology 47(5): 279-287. 


$$
-4505-
$$

\section{APPENDIX}

Table A1. Number of 16S rDNA gene sequences derived from 4 libraries

\begin{tabular}{c|c|c|c}
\hline Sample & No. obtained sequences $\geq \mathbf{4 0 0}$ bp & Bases (bp) & Average length (bp) \\
\hline Monoculture alfalfa & 10405 & 4123641 & 396.31 \\
Alfalfa intercropping & 14044 & 5565166 & 396.27 \\
Monoculture wheat & 13043 & 5165858 & 396.06 \\
Wheat intercropping & 11902 & 4716160 & 396.25 \\
\hline
\end{tabular}

Figure A1. Rarefaction curves indicating the observed number of OTUs at $3 \%$ genetic distances in 4 libraries. Alfalfa monoculture (AM), intercropping alfalfa (IA), wheat monoculture (WM), and intercropping wheat $(I W)$

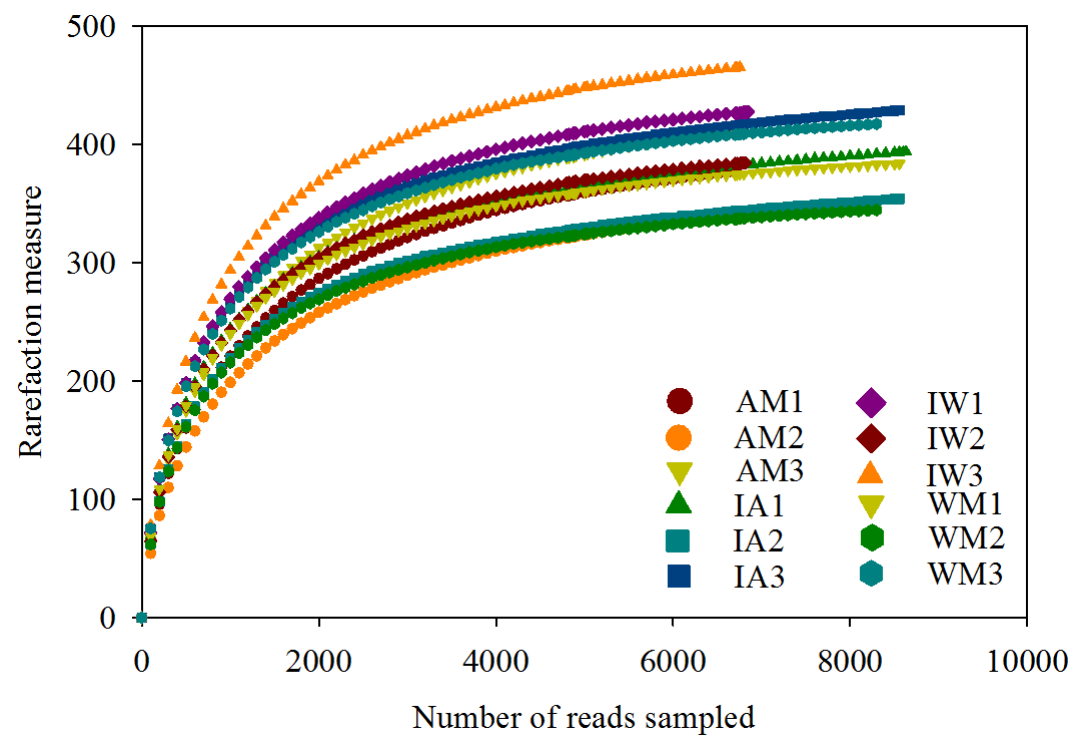

Figure A2. Composition of bacterial taxonomic groups

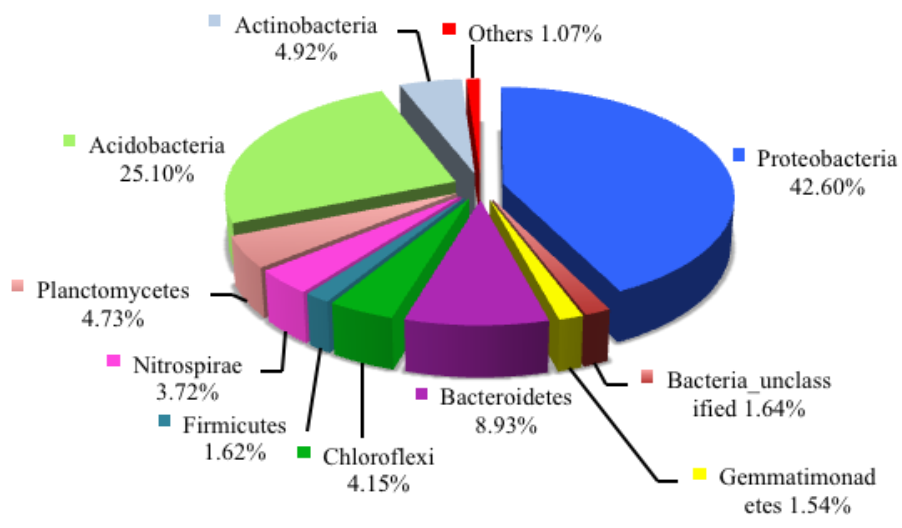

